\title{
Evaluation of functionality in families with a member diagnosed with bipolar disorder
}

\author{
Maria-Silvia Trandafir \\ From $1^{\text {st }}$ International Congress on Neurobiology and Clinical Psychopharmacology \\ and European Psychiatric Association Conference on Treatment Guidance \\ Thessaloniki, Greece. 19-22 November 2009
}

\section{Background}

Affective disorders represent a pathology with cronic, recurent character, in a continuous growth which affect different categories of population causing serious socioeconomical desinsertion and expensive costs The notion of "maniac-depressive psychosis" was used for the first time by Krepelin in 1913, in the German region. K. Leonhard and Scandinavic Psychiatry and later on Angst and Peris differentiate the notions of "mono-unipolar and bipolar psychosis"

Duner (1976), divides the bipolar disorder into the first degree - major depression and mania, second degree bipolar disorder - major depression and hipomania.

The family is an important support for the patients. Family therapy contribute to the increase of quality of the patient and his/her family life.

\begin{abstract}
Aims
The study intends to focus on the functionality of a family with a patient diagnosed with biplolar disorder tip II. The results will be compared to a witness sample of families that do not have a member that suffers from a mental disease.
\end{abstract}

\section{Materials and methods}

A semple of 10 famlies that summed up a number of 30 persons have been included in the study. The gender repartition was $63,3 \%$ (19 males) and 36,6\% (11 females). People aged 17 to 69 were included in the study, average: 42,2 years old, standard deviation 15,1, mode 26, mediana 44,5. We evaluated functionality of families using The Family Functioning Scale (FFS). As a comparison, we used the results obtained in "The clinical study on psychodinamics over a family's relationships in the

Alexandru Obregia Hospital, Unit 7, Bucharest, Romania psychiatrical clinic", published by Ph.D. Silvia Trandafir in 2005, from which we have taken the data regarding the so-called normal families in Romania. In the abovementioned paper, a sample of 132 families were studied, sample that summed-up 323 persons.

\section{Results}

The following results were gathered: positive affect 32,23 , communication 36,4 , conflictuality 25,9 , worries 41,23 , and rituals 40,36 . The results represent an average of the values obtained through the scale in the depression periods and those of hipomania.

\section{Conclusions}

The fifth components that come from the FFS measure the most important aspects of the functionality of the families. The study revealed significant differences between the component of the two types of families (with and without sick members). Families have a big adaptability to everyday problems, one may speak of a normality of the families with a Second Degree Bipolar Affective Disorder member (patient).

Published: 22 April 2010

\section{References}

1. Tavitian Marck, Grebstein CLawrance, Lubiner Judith: Dimension of family Functioning. Rhod lland New-York 1987.

2. Nichols PMichael, Schwartz CRichard: Family Therapy, Concepts and Methods VI th tr Romana, Bucharest. 2005.

3. Malagoli Marisa Togliati: Familie multiproblemetiche, nuova edizione. Carocci Editore, Roma 2004.

4. Akerman N: Psicodinamica della vita familiare. Ed. Bollati Boringheri, Torino 1999.

\section{doi:10.1186/1744-859X-9-S1-S200}

Cite this article as: Trandafir: Evaluation of functionality in families with a member diagnosed with bipolar disorder. Annals of General Psychiatry 2010 9(Suppl 1):S200. 